\title{
Microscale Hydrogen and Nitrogen Isotopic Distributions in Pristine CM Chondrite Asuka 12236
}

\author{
L. R. NitTleR ${ }^{1, *}$, C. M. O’D. AleXANDER ${ }^{1}$, AND M. J. \\ VERDIER-PAOLETTI ${ }^{1}$, \\ ${ }^{1}$ Carnegie Science Earth and Planets Laboratory, Washington \\ DC, USA.*Inittler@ciw.edu
}

Insoluble organic matter (IOM) in meteorites displays a wide range of $\mathrm{H}, \mathrm{C}$, and $\mathrm{N}$ isotopic ratios on whole-rock to sub- $\mu \mathrm{m}$ scales $[1,2]$ and the impact of parent-body processing on its properties is complex and poorly understood. The Antarctic meteorite Asuka 12236 has been recently observed to be one of the most pristine, least-altered CM chondrites, on the basis of its mineralogy, high abundance of presolar grains, and bulk $\mathrm{D} / \mathrm{H}$ and ${ }^{15} \mathrm{~N} /{ }^{14} \mathrm{~N}$ ratios $[3,4]$. We report here a NanoSIMS isotopic survey of $\mathrm{H}$ and $\mathrm{N}$ isotopes in this meteorite. A total area of $6400 \mu \mathrm{m}^{2}$ was scanned in two sessions. First, $\mathrm{C}$ and $\mathrm{N}$ isotopes were measured along with ${ }^{16} \mathrm{O},{ }^{28} \mathrm{Si}$ and ${ }^{27} \mathrm{Al}^{16} \mathrm{O}$ with a $\sim 100-\mathrm{nm}^{\mathrm{Cs}^{+}}$primary beam, followed by re-measurement of the same areas for $\mathrm{H}, \mathrm{D}$, and ${ }^{12} \mathrm{CH}$ with a higher current and consequently larger size beam of $\sim 300 \mathrm{~nm}$. Individual C-rich regions of interest (ROIs) were defined in the images, correlated between the two sessions, and their $\mathrm{H}, \mathrm{C}$ and $\mathrm{N}$ isotopic ratios determined. As seen in other chondrites, $\mathrm{C}$ is mostly apparent as sub- $\mu \mathrm{m}$ to $\mu \mathrm{m}$-sized inclusions, most of which have $\mathrm{H}$ and $\mathrm{N}$ isotopic compositions consistent with the average bulk values [4] of $\delta \mathrm{D}=141 \%$ and $\delta^{15} \mathrm{~N}=58 \%$. About $5 \%$ of the ROIs had noticeably higher D and/or ${ }^{15} \mathrm{~N}$ enrichments ("hotspots") with $\delta \mathrm{D}$ values up to $6500 \%$ and $\delta^{15} \mathrm{~N}$ up to $1100 \%$. The $\delta \mathrm{D}$ and $\delta^{15} \mathrm{~N}$ values are not highly correlated, with $\sim 2 / 3$ of the ROIs being enriched in both isotopes, the others only in either $\mathrm{D}$ or ${ }^{15} \mathrm{~N}$. No $\mathrm{C}$ isotope anonalies associated with organic matter were observed. Some of the hotspots are clearly associated with carboanceous nanoglobules. The fraction of hotspots and maximum isotope enrichments are higher than seen before in Murchson [e.g., 1] but lower than seen in CR chondrites. These results provide further evidence that Asuka 12236 is less altered than other CMs but not as primitive as many CR chondrites.

[1] Busemann H., et al. (2006) Science, 312, 727. [2] Alexander C. M. O'D., et al. (2017) Chem. der Erde, 77, 227. [3] Kimura M., et al. (2019) $82^{\text {nd }}$ Meeting of the Meteoritical Society, Abstract 6042. [4] Nittler L R., et al. (2020) $51^{\text {st }}$ Lunar and Planetary Science Conf., Abstract 2276. 